\title{
Repair of a distal leg defect using the latissimus dorsi free flap
}

JON F. HARRELL, MAJ, MC DANIEL SPEILMAN, COL, MC ALLAN C. SMITH, COL, MC

The development of free tissue transfer utilizing microvascular anastomotic technique has enhanced the ability of the surgeon to salvage difficult wound problems. A case report is presented of a patient who had a soft tissue defect. In experienced hands, this technique yields flap survival rates of $95 \%$. The article describes common tissue donor sites, indications for free tissue transfer, and details the main advantages and limitations.

The many muscle free flaps available for lower extremity reconstruction are the latissimus dorsi, ${ }^{1}$ internal oblique ${ }^{2}$ gracilis, ${ }^{1}$ and rectus abdominis ${ }^{3}$ flaps. Cutaneous flaps from the scapula, ${ }^{4}$ groin, and radial forearm ${ }^{5}$ also have been used in lower extremity reconstruction.

The latissimus dorsi offers a $10 \times 30 \mathrm{~cm}$ paddle of skin while still allowing primary closure of the donor defect. However, the muscle area available is much greater; it covers virtually one half of the posterior hemithorax. Further, skin-grafted muscle shows satisfactory cosmesis and frequently has a better contour than skin-muscle flaps. ${ }^{1,5,6}$ By dissecting the thoracodorsal vessels proximally to the origin of the subscapular vessels off of the axillary artery and vein, arteries with diameters of 3 to 4 $\mathrm{mm}$ and veins with diameters of 4 to $6 \mathrm{~mm}$ (lengths, 7 to $9 \mathrm{~cm}$ ) are available for anastomosis, which makes the procedure easier technically..$^{8-10}$

In this article, we describe the reconstructive technique used for a young boy with a severe lower extremity injury. The indications and uses of free flaps, along with their advantages and disadvantages, are discussed.

\section{Report of case}

A 12-year-old boy was struck by an automobile while riding his bicycle in the summer of 1986 . His injuries included numerous abrasions and a "degloving" injury of the right-sided leg and ankle laterally and distally. Initial treatment at a local hospital included debridement of nonviable tissue and sectioning of the exposed and injured extensor digitorum longus tendons, which were buried under viable muscle by the surgeon. Also, the anterior tibial artery was interrupted at the level of the extensor retinaculum.

The patient was transferred to the Walter Reed Army Medical Center, Plastic Surgery Service, three days after injury. Evaluation revealed a "degloving" defect across the anterolateral, distal leg and ankle, with loss of the distolateral fibula and exposure of the cuneiform and cuboid bones. The soft-tissue defect measured $6 \times$ $18 \mathrm{~cm}$ (Fig 1). Functionally, the patient was able to extend his large toe and dorsiflex his ankle; plantar sensation was noted to be normal.

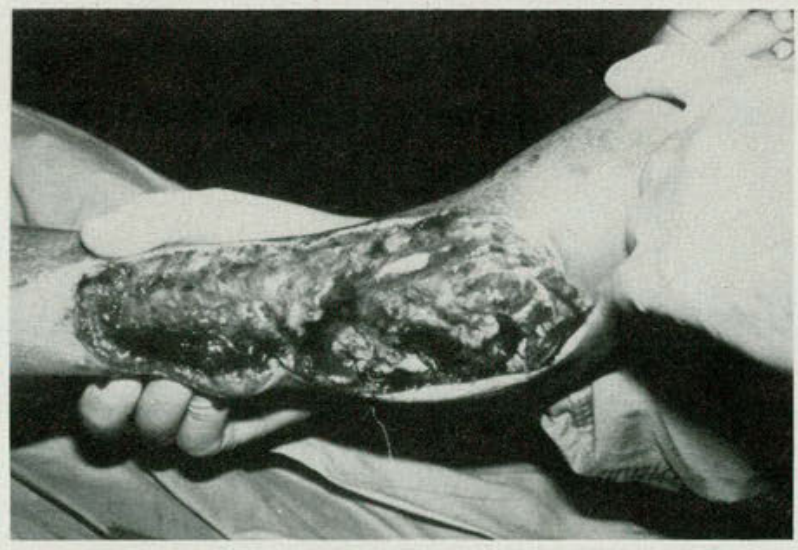

Fig 1. Extent of soft-tissue defect at time of reconstruction. Note exposure of tibialis anterior tendon and loss of skin measuring $6 \times 18 \mathrm{~cm}$. 


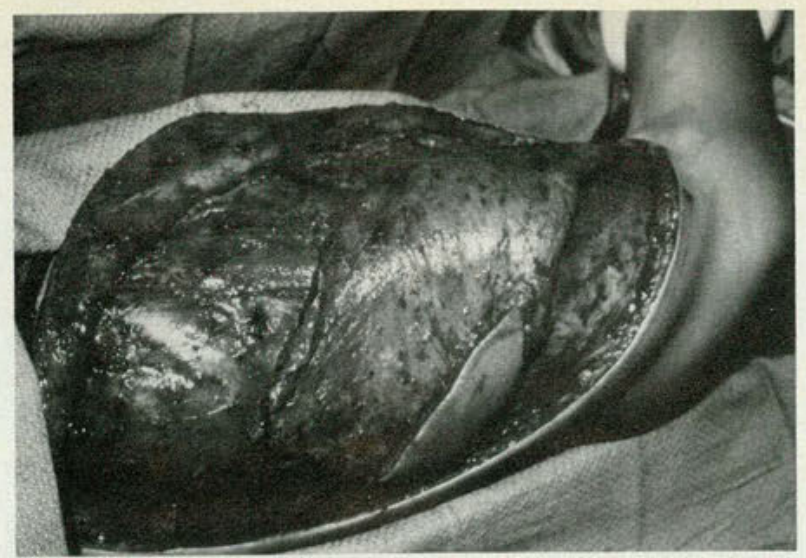

Fig 2. Latissimus dorsi muscle stil attached to vascular leash prior to transfer. Muscle is harvested through an incision extending from the axilla down along the free border of the latissimus dorsi muscle. A small skin paddle still attached to the muscle was removed later because of excessive bulkiness.

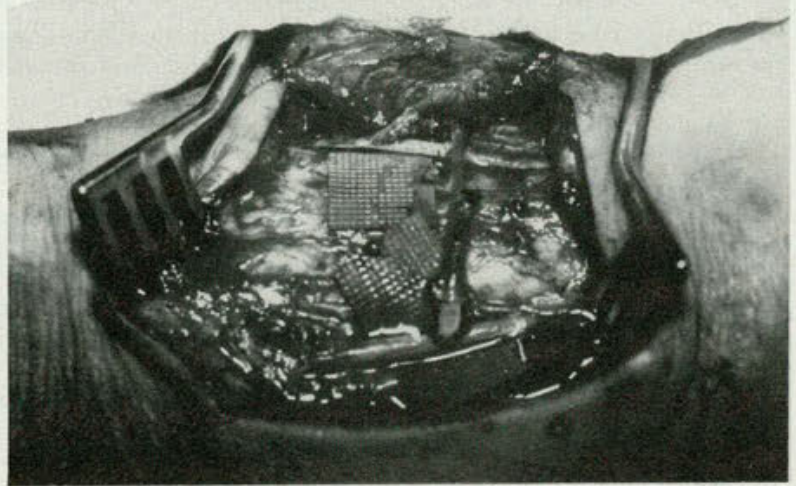

Fig 4. Completed arterial anastomosis between the subscapular and posterior tibial vessels. The majority of the flap is covered by the sponge at the top of the photograph.

Arteriography demonstrated a patent posterior tibial artery, occlusion of the anterior tibial artery at the an$\mathrm{kle}$, and associated narrowing of the peroneal artery distally.

The patient's wound appeared clean, and, on the seventh day after injury, he underwent a free-tissue transfer of a latissimus dorsi muscle flap to cover the leg defect (Figs 2,3). This was accomplished by means of a microvascular, end-to-side anastomosis between the posterior tibial and subscapular arteries and veins (Fig 4). The transferred muscle was covered using a split-thickness skin graft obtained from the patient's thigh.

The patient did well postoperatively. Suction drains, which had been placed during surgery, were removed from the donor and recipient sites on the fifth and sixth postsurgical days, respectively. He was kept at bedrest with his leg elevated for nine days, after which he was allowed to be in a wheelchair with his leg elevated for another 15 days. He then was placed in a nonweightbearing cast. The flap remained healthy without any signifi-

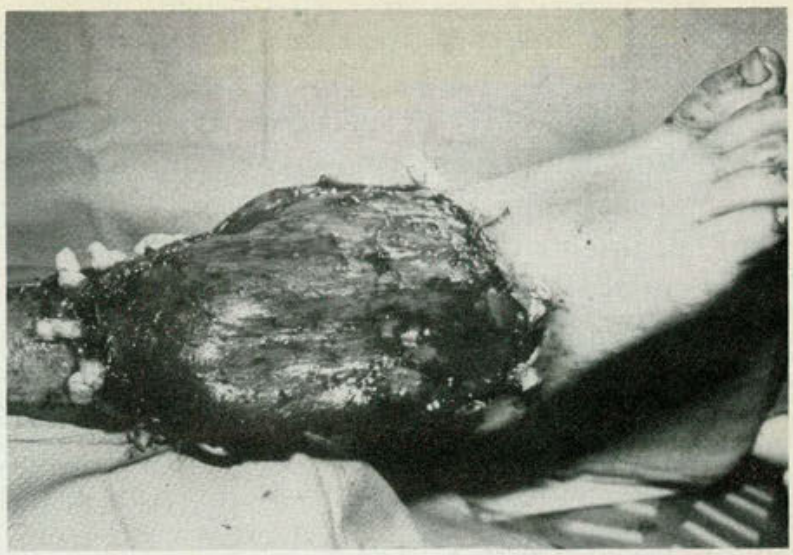

Fig 3. Latissimus dorsi muscle after being sutured into the defect.

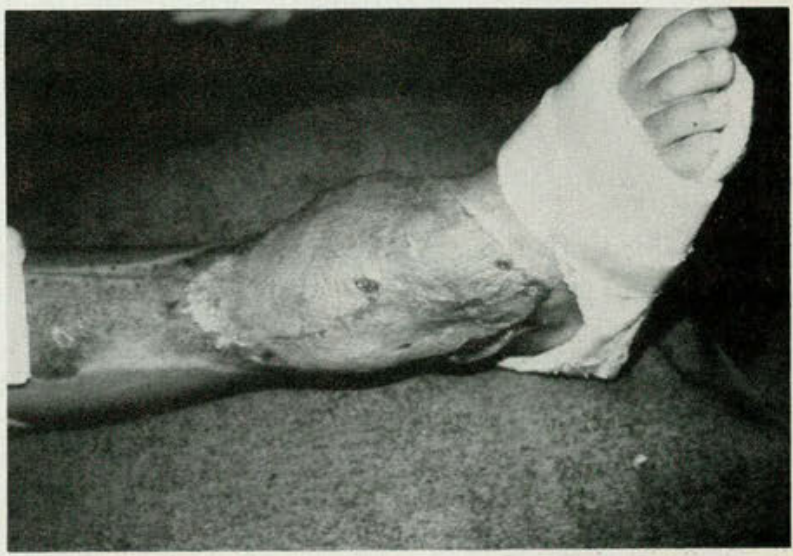

Fig 5. Flap with skin graft three weeks after surgery. A further decrease in muscle bulk is expected, because the muscle will continue to atrophy due to sectioning of its nerve at the time of transfer.

cant areas of breakdown (Fig 5) at 3 weeks' postoperative when he was last seen in the clinic.

The patient now has a stable skin soft-tissue coverage, under which further operations can be performed as necessary on his ankle and tendons should tendon grafting be deemed necessary.

\section{Discussion}

\section{Indications and advantages}

Indications for free-tissue transfer, whether of softtissue origin, bony origin, or both, are as follows: soft-tissue defects of the foot and lower one third of the leg ${ }^{1,8}$; treatment of chronic bone infection, providing that there is sufficient debridement and satisfactory apposition of the muscle to the bone ${ }^{3,8,11,12}$; combined soft-tissue and bone loss $(<6$ $\mathrm{cm})^{1}$; in preparation for bone grafting; or severe stasis and chronic ulceration secondary to vasculitis from systemic disease. ${ }^{1}$ 
The introduction of free-tissue transfer for coverage of difficult wounds has increased greatly the surgical armamentarium of the reconstructive surgeon. Whether transferred as a myocutaneous flap or simply as a muscle flap that is subsequently skin grafted, this method of reconstruction offers several benefits: First, it provides richly vascular tissue, which enhances the local blood supply of the injured area. ${ }^{10,13}$ Second, it gives adequate padding over bony prominences and protective cover for nerves, vessels, and tendons. Even when transferred as a muscle flap that is skin grafted, the graft will remain healthy under most conditions of use. ${ }^{14}$ Third, it also offers stable coverage under which further surgery, such as tendon transfer and bone grafts, can be undertaken safely. Fourth, it allows the surgeon an important option in dealing with injuries localized to regions that are difficult to cover with either local flaps or skin grafts, such as the distal third of the leg. Fifth, in experienced hands it yields an excellent success rate of $92 \%$ to $95 \% .^{8}$

\section{Limitations}

One major limitation of free-tissue transfer is that the surgeon must be familiar with and experienced in microvascular techniques. Additionally, the surgeon must maintain proficiency intermittently by a practice surgery. The decision to use this procedure also may be influenced by potential aesthetic problems, such as donor site scars and contour irregularities, as well as the possibility of functional losses, depending on the muscle that may be transferred.

\section{Summary}

Since their introduction into clinical practice, free flaps of skin, muscle, or both have provided the reconstructive surgeon with a valuable tool in managing difficult wounds of the distal lower extremity. Although the procedures for free-tissue transfer are demanding technically, for the experienced surgeon they yield a high success rate and help to maximize the potential for regaining function in the injured extremity.

1. Swartz WM, Mears DC: The role of free-tissue transfers in lowerextremity reconstruction. Plast Reconstr Surg 1985;76:364-373.

2. Ramasatry SS, Tucker JB, Swartz WM, et al: The internal oblique muscle flap: An anatomical and clinical study. Plast Reconstr Surg 1984;73:721-733.

3. Bunkis J, Walton RL, Mathes SJ: The rectus abdominis free flap for lower extremity reconstruction. Ann Plast Surg 1983;11:373-380.

4. Barwick WJ, Goodkine DJ, Serafin D: The free scapular flap. Plast Reconstr Surg 1982;69:779-787.

5. Shaw HW: Microvascular free flaps-The first decade. Clin Plast Surg 10:3-20, 1983

6. Gordon L, Buncke HJ, Alpert BS: Free latissimus dorsi muscle flap with split-thickness skin graft cover: A report of 16 cases. Plast Reconstr Surg 1982;70:173-178.

7. May JW Jr, Gallico GG III, Jupiter J, et al: Free latissimus dorsi muscle flap with skin graft for treatment of traumatic chronic bony wounds. Plast Reconstr Surg 1984;73:641-651.

8. Serafin D, Voci VE: Reconstruction of the lower extremity: Microsurgical composite tissue transplantation. Clin Plast Surg 1983;10:55-72.

9. Maxwell GP, Stueber K, Hoopes JE: A free latissimus dorsi myocutaneous flap. Plast Reconstr Surg 1978;62:462-66.

10. Serafin D, Sabatier RE, Morris RL, et al: Reconstruction of the lower extremity with vascularized composite tissue: Improved tissue survival and specific indications. Plast Reconstr Surg 1980;66:230-241.

11. Weiland AJ, Moore JR, Daniel RK: The efficacy of free tissue transfer in the treatment of osteomyelitis. J Bone Joint Surg [Am] 1984;66:181193.

12. Mathes SJ, Alpert BS, Chang N: Use of the muscle flap in chronic osteomyelitis: Experimental and clinical correlation. Plast Reconstr Surg 1982;69:815-829.

13. Maxwell GP, Manson PN, and Hoopes JE: Experience with thirteen latissimus dorsi myocutaneous free flaps. Plast Reconstr Surg 1979;64:18.

14. May JW Jr, Lukash FW, Gallico GG: Latissimus dorsi free muscle flap in local extremity reconstruction. Plast Reconstr Surg 1981;68:603607.

The views expressed herein are those of the authors and do not necessarily reflect the views of the US Army or the Department of Defense.

From the Plastic Surgery Service, Walter Reed Army Medical Center, Washington, D.C.

Reprint requests to Dr Harrell, Department of Plastic Surgery, Tripler Army Medical Center, Honolulu, HI 96859. 